\title{
Curing Pressure Influence of Out-of-Autoclave Processing on Structural Composites for Commercial Aviation
}

\author{
Vasileios M. Drakonakis, ${ }^{1,2}$ James C. Seferis, ${ }^{1}$ and Charalambos C. Doumanidis ${ }^{3}$ \\ ${ }^{1}$ Polymeric Composites Laboratory, GloCal/F.R.E.E.D.O.M., 3131 Western Avenue M526, Seattle, WA 98121, USA \\ ${ }^{2}$ University of Texas at Arlington, 500 West First Street, Arlington, TX 76019, USA \\ ${ }^{3}$ University of Cyprus, P.O. Box 20537, 1678 Nicosia, Cyprus
}

Correspondence should be addressed to James C. Seferis; jcseferis@aol.com

Received 6 September 2012; Revised 11 December 2012; Accepted 11 January 2013

Academic Editor: Abbas Milani

Copyright (C) 2013 Vasileios M. Drakonakis et al. This is an open access article distributed under the Creative Commons Attribution License, which permits unrestricted use, distribution, and reproduction in any medium, provided the original work is properly cited.

\begin{abstract}
Autoclaving is a process that ensures the highest quality of carbon fiber reinforced polymer (CFRP) composite structures used in aviation. During the autoclave process, consolidation of prepreg laminas through simultaneous elevated pressure and temperature results in a uniform high-end material system. This work focuses on analyzing in a fundamental way the applications of pressure and temperature separately during prepreg consolidation. A controlled pressure vessel (press-clave) has been designed that applies pressure during the curing process while the temperature is being applied locally by heat blankets. This vessel gives the ability to design manufacturing processes with different pressures while applying temperature at desired regions of the composite. The pressure role on the curing extent and its effect on the interlayer region are also tested in order to evaluate the consolidation of prepregs to a completely uniform material. Such studies may also be used to provide insight into the morphology of interlayer reinforcement concepts, which are widely used in the featherweight composites. Specimens manufactured by press-clave, which separates pressure from heat, are analytically tested and compared to autoclaved specimens in order to demonstrate the suitability of the press-clave to manufacture high-quality composites with excessively reduced cost.
\end{abstract}

\section{Introduction}

Autoclaving is among several manufacturing methods for polymeric composites. It is a process mainly utilized in the field of aviation as it guarantees the highest quality for composite structures. The autoclaving process brings the individual prepreg plies together and consolidates them through pressure into a uniform solid material. Elevated temperatures are necessary to initiate and complete the curing reaction for thermoset-based prepregs. This work focuses on an effort to analyze in a fundamental way the applications of pressure and temperature separately during prepreg consolidation. A controlled pressure vessel has been designed that applies pressure during the curing process while the temperature is being applied locally by heat blankets. This vessel gives the ability to design manufacturing processes with different pressures while applying temperature at desired regions of the composite. The role of pressure on the curing extent and its effect on the interlayer region are also tested in order to evaluate the consolidation of prepregs to a completely uniform material. Such studies may also be used to provide insight into the morphology of the interlayer reinforcement concepts such as $z$-direction oriented aligned carbon nanotubes (CNTs) that have shown promise in increasing interlaminar toughness of unidirectional prepregs $[1,2]$. Independent variation of temperature and pressure allows these effects to be understood on the CNT alignment and overall penetration into the adjacent bridged plies.

The combination of heat and pressure applied on prepreg plies is necessary in order to consolidate them into a fiberreinforced polymer composite based on fabricated prepregs. Furthermore, the curing reaction initiation and completion of thermosetting prepreg materials requires elevated temperatures. Several techniques, such as press- or autoclave operations, are available to conduct this manufacturing operation [3]. For manufacturing high-performance polymeric composite materials, autoclaving is the most common technique, mainly due to the versatility and comprehensiveness of this processing type and the large parts production capability with relatively inexpensive tooling [3]. Nevertheless, long tool 
assembly and processing time make this method a costly, inefficient, and unattractive process for high-volume manufacturing. This is the main reason for utilizing autoclaving in aerospace industrial applications, where the importance of materials outweighs cost. The option of a more affordable technique though with similar quality potential is still very attractive.

Although autoclaving is the manufacturing process used for almost all the polymeric composite parts utilized in aerospace field, in our days, the economic situation requires solutions that will be more affordable than the conventional autoclave processing without sacrificing quality. Efforts are made to manufacture materials of the same quality but with less expensive methods such as vacuum-assisted resin transfer molding (VARTM) [4-7], resin infusion techniques $[8,9]$, and resin transfer molding (RTM) techniques [10]. The weaknesses of these methods are the inability to control temperature and pressure while curing as well as nonuniformity throughout the structure, which is translated in void formation. Furthermore, these techniques are not able to utilize prepregs apart perhaps from the RTM techniques when the mold is able to heat up (e.g., in a press) [11, 12]. The autoclave, on the other hand, is designed to cure prepregs, and it gives a neat uniform structure with controlled size of voids or no voids at all $[3,12,13]$. The necessity of prepregs in aerospace composite structures is carried in the prepreg nature to be first, pre-wetted with resin without letting voids to be formed, second, responsible for allowing a high-quality composite part, third, of assistance in a much faster manufacturing process compared to the processed mentioned earlier as there is no need for resin handling, and finally, able to control the desired accumulation of resin into the composite part $[3,12,13]$. The latter reasons make it inevitable for the aerospace field to stop utilizing prepregs; as a consequence, the affordability has to focus on the method. A process that will be able to cure prepregs with the same quality as autoclave but in lower cost is in demand.

Such an affordable method is the pressurized vessel or "repair clave," such as the one manufactured by Heatcon Composite Systems in Seattle, WA, USA. The main characteristic of this clave is the separation of pressure and temperature while curing. Despite its first purpose of being utilized as a repair technique in aviation, this work brings the beginning of a breakthrough to prove that this technique can be used for manufacturing as well, without major differences in the final material product quality. Carbon fiber prepreg panels were manufactured in the clave under different pressures, and they were tested in dynamic mechanical analysis (DMA) and differential scanning calorimetry (DSC) to investigate the pressure effect on the dynamic mechanical properties as well as on the curing quality of the materials. The description of future work needed to further investigate this effort is also mentioned in this paper [14].

\section{Autoclave Processing}

High-quality polymeric composites manufacturing requires high-pressure procedures of 70 to $90 \mathrm{psi}$ such as autoclaving, which is used in high tech applications and mainly in aviation.

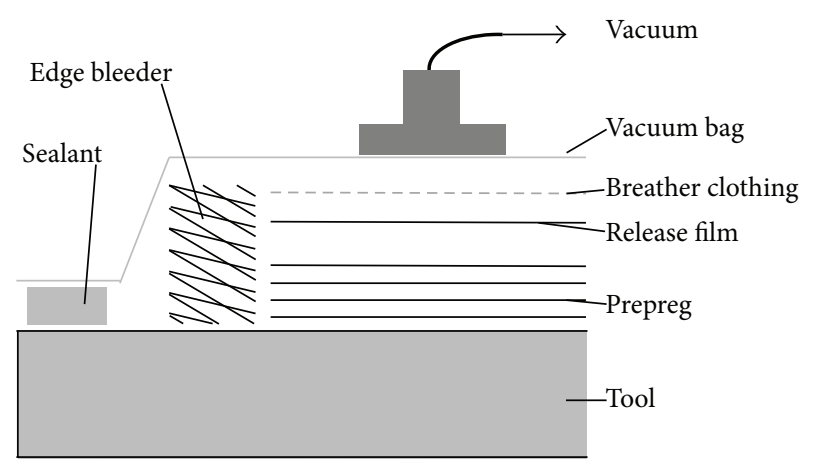

Figure 1: Autoclave entire lay-up [14].

The autoclave is a device that can generate a controlled pressure and temperature environment. While several autoclave types are available, all consist primarily of three units: a pressure vessel, a heating/cooling system, and a control unit. When prepreg-based composites are processed using autoclaves, they undergo several steps prior to the actual autoclaving. These steps usually follow a strict procedure because they have been found to affect the final properties of the composite [15]. Similar to other composite manufacturing techniques, the prepreg materials are stacked or laid-up to yield a laminate of the required dimensions. The entire layup including prepreg plies, release film, and breather cloth is then covered with a vacuum bag as shown in Figure 1. Since the pressures in the bag and autoclave are different, a compacting force that corresponds to this pressure difference is exerted on the laminate. Through this feature and the flexible characteristics of the vacuum bag, the pressure is always acting normally to the laminate surface, which leads to a uniform pressure distribution. This uniform pressure distribution, which is applied continuously throughout cure, reduces the risk of void formation, especially when dealing with thermosetting prepreg materials [16-21].

After completion of the vacuum bag, the laminate can be autoclaved using a certain temperature and pressure profile. In composite fabrication, the autoclave is usually pressurized with nitrogen so that fire hazards imposed by the exothermic prepreg materials are reduced [22]. Heat is applied using heat exchangers in conjunction with fans that assist heat transfer $[3,14,23]$.

Generally for autoclaves, the usual processing procedure for thermosetting prepreg curing is to firstly increase pressure and right afterwards heating the autoclave at a chosen heating rate to the desired temperature. According to most fluids behaviour, the viscosity of the matrix will decrease with this temperature rise. As a result, at elevated temperature, the resin will freely flow, facilitating the consolidation process until eventually the chemical cross-linking starts occurring and forming gelation. At this point, the resin will soon change from a liquid into a solid, and it will start preventing viscous flow. It is, therefore, important that the chemorheology of the prepreg resins is known in order to complete consolidation and volatile removal prior to resin gelation. A typical autoclave cycle containing two isothermal dwells is shown 


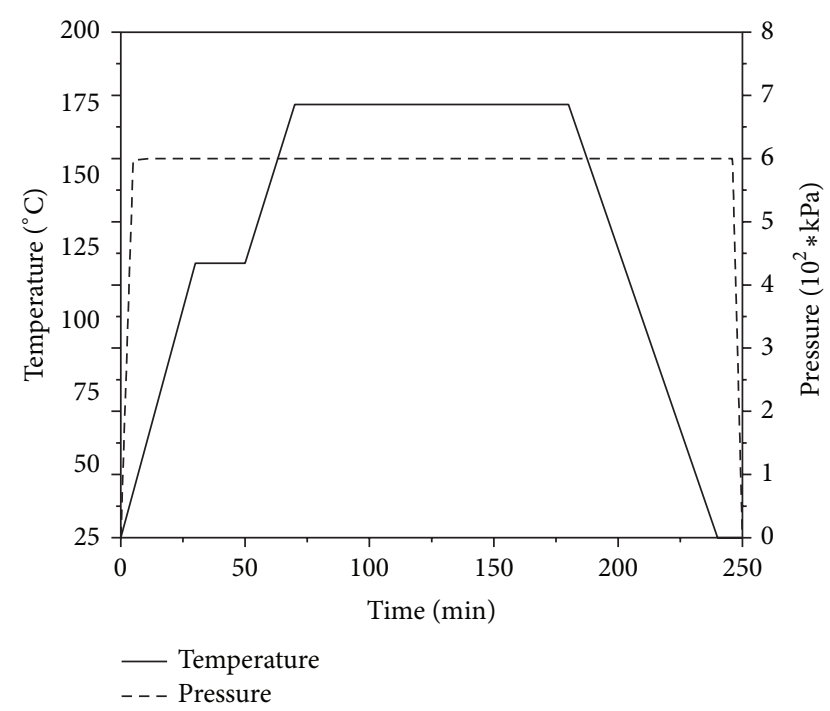

FIgURE 2: Typical diagram of temperature and pressure profile for curing in a clave [14].

in Figure 2. The first dwell is performed to prolong the time range for consolidation and eventually to prereact the matrix to reduce the risks of large exotherms. The second dwell is the actual cure step. Most commercial epoxy-based prepreg systems require cure temperatures of $121^{\circ} \mathrm{C}$ or $178^{\circ} \mathrm{C}$. The application of pressure assists the consolidation and helps suppress voids in the laminates.

Nevertheless, high pressures might eventually drive too much resin out of the fiber bed leading again to void formation, resulting from resin starvation this time. Even though much research has focused on the autoclave consolidation and processing optimization, the developed models are of limited use. So, many variables such as prepreg type, part dimensions, vacuum bag materials, lay-up, and processing conditions influence the consolidation that the composites industry has determined almost all operating conditions by trial and error. Consequently, the aerospace industry has tried to employ standardized procedures. For instance, the majority of these parts are cured using $121^{\circ} \mathrm{C}$ or $178^{\circ} \mathrm{C}$ standard cure cycles. In addition, one distinguishes between high-, intermediate-, and low-flow prepreg systems. Considering this information, the lay-up can be adjusted such that the optimum part qualities can be accomplished $[3,14,15,18,19$, 23].

\section{Pressurized Vessel}

The repair clave (Figure 3 ) is a semiportable pressure vessel, designed to provide controlled temperature, vacuum, and pressure for repair of composite and metal-bonded parts that require higher pressures than can be achieved by vacuum only. Unlike a conventional autoclave, there are no internal heating elements in the vessel; so, the heat for curing is derived from heat blankets or other heating elements. This study focuses mainly on the cures that are done with the help of heat blankets.

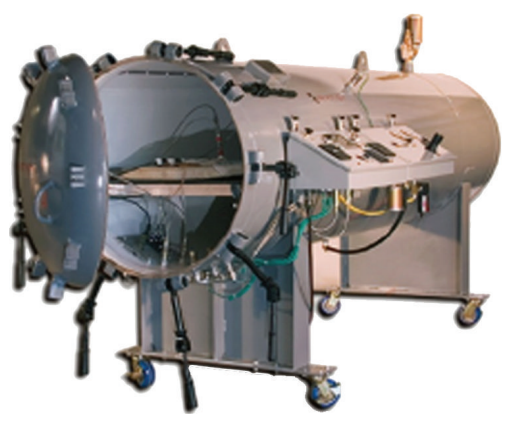

Figure 3: Heatcon Composite System-Repair Clave Model HCS3100 [28].

Although the main difference between a repair clave and an autoclave comes from the fact that one is mainly dedicated to repairs of composite parts while the other for manufacturing, it is believed that a repair clave could become a useful tool in manufacturing simple parts at a much more affordable cost. Currently, autoclaves could be used for repairs also, if extensive rebuild of a part is needed. The repair clave can be referred to as an affordable autoclave, as it reaches almost the same pressures, but it permits the use of localized heat which results in much more economical cures. However, one needs to investigate if the quality of a repaired part can be maintained at the standards of a part manufactured through an autoclave.

There are of course many differences that put the two claves apart, but by understanding these differences, one can see at which common point the repair clave might be used as a possible future autoclave for manufacturing simple composite parts (Table 1).

\section{Experimental}

In order to investigate the role of pressure during manufacturing, when it is applied separately from the temperature, and how it affects the final material, four different plates were manufactured under four different process pressures. The four different pressures were $0,30,50$, and 70 psi. Each panel had eight plies of woven carbon fiber prepreg (type: Cytec Engineered Materials BMS 8-297, HMF 934 Carbon Prepreg Fiberite 934, resin density $1.3 \mathrm{~g} / \mathrm{cc}$ ). The configuration of the plies is $(0,90, \pm 45)$ s. Dimensions of the panels were $10 \times 8$ inches with an approximate thickness of $1 \mathrm{~mm}$. After being manufactured, the panels were cut to appropriate samples for dynamic mechanical analysis and differential scanning calorimetry analyses.

4.1. Processing. The prepreg plies were stored in a refrigerator at a temperature below $0^{\circ} \mathrm{F}$ or $-17.7^{\circ} \mathrm{C}$. They were cut to the desired dimensions and orientation. After that, the lay-up took place. The plies were placed in the desired configuration, and on top of them, all the layers described in Table 2 were applied.

The vacuum has to be at least 22 in $\mathrm{Hg} 0^{\circ} \mathrm{C}$. When the desired vacuum is accomplished, the laid-up panel enters the vessel. The vessel is sealed, and the pressure can be adjusted 
TABLE 1: Repair clave and autoclave advantages and disadvantages [14, 28, 29].

\begin{tabular}{ll}
\hline & Repair clave (for the model in Figure 3) \\
\hline Qualification & Qualified for repairing composite parts \\
Design considerations & $\begin{array}{l}\text { For a vessel of } 4 \mathrm{~m}(12 \mathrm{ft}) \text { length and } 0.9 \mathrm{~m}(3 \mathrm{ft}) \\
\text { diameter less than } 2 \mathrm{~cm} \text { thickness needed }\end{array}$
\end{tabular}

General installation

Operating pressure

Pressurizing system

Heating system

Electrical system

Vacuum system

Control system

Loading system

Safety

Affordability

Repaired/manufactured parts
The only extra equipment it needs is a commercially available air compressor

Max to 75 psi $(517 \mathrm{kPa})$

Higher pressures can be achieved upon request

Through an external air compressor (e.g., for the model in Figure 3, $305 \mathrm{~cm}$ long, a 5 HP, 114 liters (30 Gallon) pump fills the clave at a rate of $1 \mathrm{psi} / \mathrm{min}$ )

Through heat blankets. Heat blanket thermal uniformity is essential for the curing quality. If the heat-up rates for the heat blankets are not respected, cracks can appear in the structures

"Plug-in wall" (e.g., electrical supply: 90 Volts AC to 264 Volts AC $47 \mathrm{~Hz}$ to $63 \mathrm{~Hz}, 0.15 \mathrm{Amps}$; power 50 Watts)

Similar system

Similar system

Similar system

Has a pressure relief valve in case of overpressure; because the temperature is separated from the pressure, there is a decreased risk possibility The electrical system, reduced need for safety features, reduced thickness of vessel, and therefore decreased manufacturing costs

Results from a market investigation analysis are indicatively presented to give a picture of the low-cost press-clave processing: sales price: $70 \% \pm 10 \%$ less expensive, operation cost: $80 \% \pm 10 \%$ less expensive, maintenance cost: $30 \% \pm 10 \%$ less expensive

Limited geometries that can be created/repaired due to the 2D heat blanket geometry; also, usage of heat blankets limits the number of plies that can be completely cured
Autoclave

Qualified for manufacturing and repair of composite parts

Thickness of vessel has to be large, as when pressure and temperature are applied together the deformation of the vessel is larger (e.g., for a $3 \mathrm{~m}$ $(9 \mathrm{ft})$ autoclave, $0.6 \mathrm{~m}(2 \mathrm{ft})$ diameter, temperature < $343^{\circ} \mathrm{C}\left(650^{\circ} \mathrm{F}\right)$, a minimum $4.5 \mathrm{~cm}$ thickness is needed)

Installation is an important consideration: foundation, cooling water supply, electrical supply, gas (if used for heating), and pressurization medium supply and exhaust arrangements.

Max operating pressure to $85 \mathrm{psi}(586 \mathrm{kPa})$

Three pressurization gases are typically used for autoclaves: air, nitrogen, and carbon dioxide

Gas heating is regularly used in autoclaves with maximum operating temperatures of 450 to $540^{\circ} \mathrm{C}$ $\left(850\right.$ to $\left.1000^{\circ} \mathrm{F}\right)$. Steam heating is often used for autoclaves operating in the 150 to $175^{\circ} \mathrm{C} \mathrm{(300} \mathrm{to}$ $350^{\circ} \mathrm{F}$ ) range. Most small autoclaves (under $2 \mathrm{~m}$, or $6 \mathrm{ft}$ in diameter) are electrically heated. Gas circulation provides mass flow for temperature uniformity and heat transfer to the part load. However, gas stream can cause thermal or mechanical shock on the manufactured parts

Even small autoclaves are not designed to just plug in and run (e.g., electrical supply: 230 Volts $\mathrm{AC} / 50 \mathrm{~Hz}$ (110 Volts on request); power: 450 Watts) Similar system

The cure cycle is controlled by feedback from thermocouples, transducers, and advanced dielectric and ultrasonic sensors.

Computer-controlled systems are used, but they are far more complex

Similar system

Use of pressurized gas to cure has redundant safety features on any autoclave because of the potential seriousness of any malfunction

High costs can come from various factors; electrical consuming system, gas used for pressurization (nitrogen can be very expensive and air is very dangerous), requires redundant safety features

Theoretically, any 3D geometry can be manufactured. Higher number of prepreg plies can be processed at the same time. However, when used for repair, areas not being repaired are subject to high temperatures which may cause deterioration to existing bonds and finishes to the desired level. Since the pressure is at the level required by the experiment, the temperature profile by controlling the heat blanket initiates curing. All the measurement parameters can be controlled by a data acquisition system attached to 
TABLE 2: Lay-up before curing in repair clave [14].

Bagging material

2 layers of $4 \mathrm{oz}$ breather

Heat blanket (in all tests presented the

heat blanket used was $120 \mathrm{~V}, 1125 \mathrm{~W}$,

and $15 * 15$ inch $(38 * 38 \mathrm{~cm}))$

Thermocouples

1 layer solid release film

1 layer bleeder (style 120 glass)

1 layer perforated release film

Carbon prepreg plies

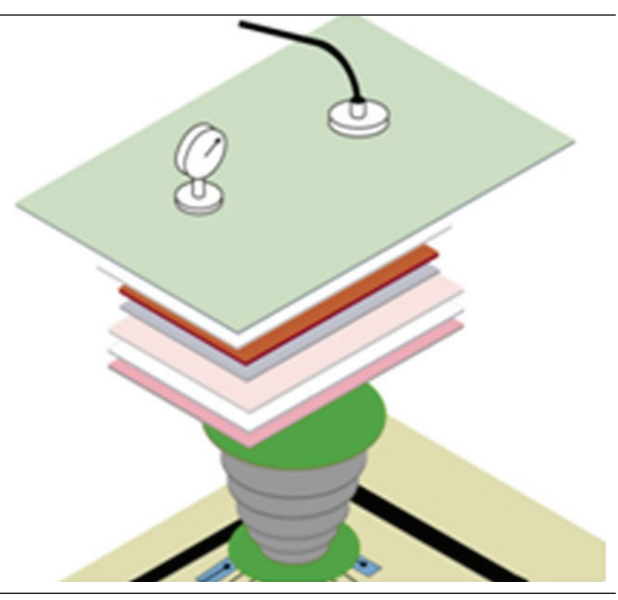

the vessel. The processing/claving lasts about 4 hours. The first step elevates the temperature up to $177^{\circ} \mathrm{C}$ with a rate $2.5^{\circ} \mathrm{C} / \mathrm{min}$, and then it goes through an isothermal period of two hours at $177^{\circ} \mathrm{C}$. After two hours in the isothermal phase, the temperature starts reducing with a rate of $2.5^{\circ} \mathrm{C}$ per min. The pressure is released, and the panel is ready after removing all the lay-up extra layers.

4.1.1. DSC Analysis. The differential scanning calorimeter that was used for these experiments was a 29 series DSC of TA Instruments, model $291^{\circ}$. Three different temperature elevating rates were used, $0.5,1$, and $5^{\circ} \mathrm{C} / \mathrm{min}$. For all of those three different rates, the samples were elevated up to $400^{\circ} \mathrm{C}$. Taking the panels manufactured in the pressurized vessel "repair clave," small samples of 5 to $20 \mathrm{mg}$ weight were cut for all the four different panels. Hence, eventually, experiments of the 4 different panels manufactured at $0,30,50$, and $70 \mathrm{psi}$ were tested in 3 different rates, that is, $0.5,1$, and $5^{\circ} \mathrm{C} / \mathrm{min}$.

\subsubsection{Scanning Electron Microscopy (SEM) Characterization.} The manufactured samples are also characterized by scanning electron microscopy, through visual examination of surfaces resulting after manufacturing. Samples were cut in dimensions of $10 \times 5 \times 1.5 \mathrm{~mm}^{3}$ so that the cross-section $\left(5 \times 1.5 \mathrm{~mm}^{2}\right)$ can be observed in the microscope. Although carbon fibers are conductive, the matrix reduces the conductivity for SEM observation, and for this reason, higher conductivity was achieved through low-vacuum sputter coating with gold. The SEM was a VEGA TESCAN 3SB microscope. Samples are exposed to an electron beam, which comes through a tungsten heated filament electron gun. Finally, the SEM resolution utilized was as high as $3 \mathrm{~nm}$ at $30 \mathrm{kV}$ and as low as $8 \mathrm{~nm}$ at $3 \mathrm{kV}$. Particularly, the CFRP samples were tested at $20 \mathrm{kV}$ and $30 \mathrm{kV}$.

4.1.3. DMA Analysis. The dynamic mechanical analyzer used for this study was a Triton DMA. Two different temperature elevating rates were used, 1 and $5^{\circ} \mathrm{C} / \mathrm{min}$. For both of these two different rates, the samples were elevated up to $300^{\circ} \mathrm{C}$. The samples were tested in 3-point bending experiments. Taking the panels manufactured in the pressurized vessel "repair clave," samples of approximately $50 \times 12 \mathrm{~mm}^{2}(l \times w)$ were cut for all four different panels and were tested in the DMA. The thickness was approximately $1.65 \mathrm{~mm}$ for the $0 \mathrm{psi}, 1.58 \mathrm{~mm}$ for the $30 \mathrm{psi}, 1.51 \mathrm{~mm}$ for the $50 \mathrm{psi}$, and $1.47 \mathrm{~mm}$ for the $70 \mathrm{psi}$. Thus, eventually, experiments of the 4 different panels manufactured at $0,30,50$, and 70 psi were tested in 2 different rates 1 and $5^{\circ} \mathrm{C} / \mathrm{min}$ under 3-point bending loading.

4.1.4. Flexural Mechanical Testing. The specimens were tested in a screw Instron machine (model 4505). More than five specimens were tested for each of the four different CFRP panels of $0,30,50$, and 70 psi manufactured. Specimens of $135 \times 12 \mathrm{~mm}^{2}(l \times w)$ were cut from the CFRP panels (the length mentioned is the gauge length). The thickness was approximately $1.65 \mathrm{~mm}$ for the $0 \mathrm{psi}, 1.58 \mathrm{~mm}$ for the $30 \mathrm{psi}, 1.51 \mathrm{~mm}$ for the $50 \mathrm{psi}$, and $1.47 \mathrm{~mm}$ for the $70 \mathrm{psi}$. The crosshead of the machine in the three-point bending test had a speed of $5 \mathrm{~mm} / \mathrm{min}$, and the test was performed from no loading state to failure. A $5 \mathrm{kN}$ load cell was utilized to perform these experiments.

4.1.5. Compression Testing. Furthermore, specimens from the panels were also tested under compression testing in the same Instron machine that flexural testing took place. Specimens of $50 \times 12 \mathrm{~mm}^{2}(l \times w)$ were cut from the CFRP panels (the length mentioned is the gauge length). The thickness is again proportional to the psi that the CFRP panel was manufactured. The crosshead of the machine in the compression test had a speed of $1.5 \mathrm{~mm} / \mathrm{min}$, and the test was performed from no loading state to failure.

\section{Results and Discussion}

5.1. Differential Scanning Calorimetry. At first, uncured samples of the prepreg with which the panels were manufactured were tested in DSC. Figure 4 shows the DSC scans for all uncured samples at $0.5,1$, and $5^{\circ} \mathrm{C} / \mathrm{min}$ heating rates. It can be easily noticed that with an increasing heating rate, the area under the peaks, which by integral represents the heat of the exothermic reaction needed for the cure, is increasing as well. Thus, the higher the heating rate, the higher the 


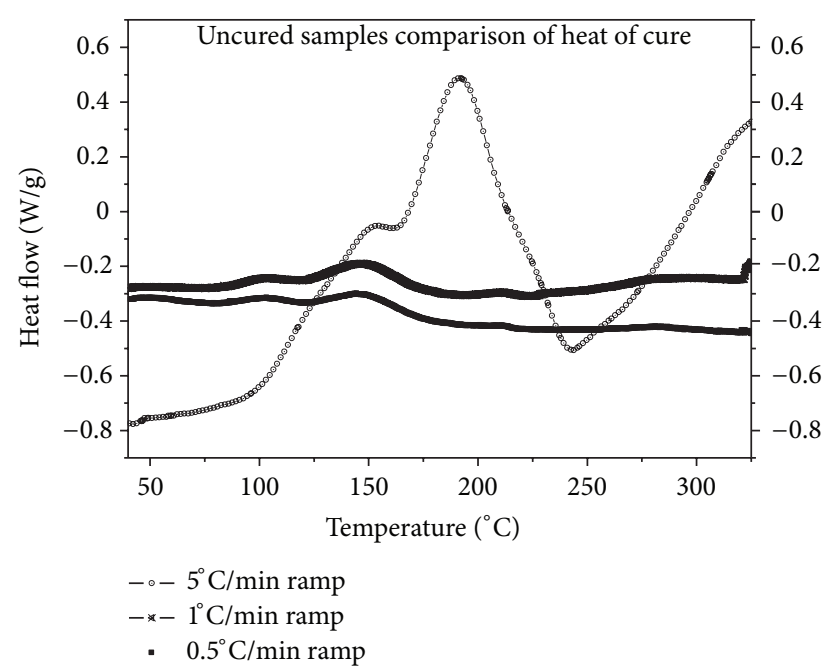

FIGURE 4: Uncured samples heat of cure comparison.

heat of cure [24-26]. This happens due to the fact that the macromolecules of the polymer need more time to respond to the temperature elevation when the later increases rapidly, due to the curing kinetics of the thermoset. Because of this time lag in the curing response, the material appears to extend and increase the exothermic heat of the polymerization reaction.

Secondly, dynamic scans from 0 to $400^{\circ} \mathrm{C}$, at heating rates of $5^{\circ} \mathrm{C} / \mathrm{min}, 1^{\circ} \mathrm{C} / \mathrm{min}$, and $5^{\circ} \mathrm{C} / \mathrm{min}$, were carried through for all different samples manufactured under the pressures of 0 psi to 70 psi. The sample weight varied from $3 \mathrm{mg}$ to $20 \mathrm{mg}$, and generally, two samples were collected for each of the pressure cases in each of the heating rates, in order to verify the results.

Graphs are provided to give an indication of the evaluation of the samples in DSC based on the exothermic peak.

In Figure 5, the comparison between the two cases 0 psi and 70 psi can be observed. For the rate of $1^{\circ} \mathrm{C} / \mathrm{min}$, the 0 psi samples present a slight elevation, which, however, cannot be considered as an exothermic reaction. At the same time, the 70 psi samples at $1^{\circ} \mathrm{C} / \mathrm{min}$ do not show any peaks or elevations at all. By checking the $5^{\circ} \mathrm{C} / \mathrm{min}$ rates, the behavior between the 0 and the 70 psi samples is similar, as although there are small exothermic peaks for both 0 and 70 psi, the integral energy does not significantly vary. As a result, it is considered that the pressure during manufacturing does not really affect the percentage of curing. Specifically, in this case, the rate of heating dominates in affecting the curing percentage.

Figure 6 shows the curves for all the 8 plies samples analyzed at a rate of $5^{\circ} \mathrm{C} / \mathrm{min}$. As it can be seen, there is no consistent pattern of behavior for all pressure cases, meaning that the curing percentage does not increase or decrease as a function of pressure, but it presents a random behavior. The two exothermic peaks are noticed for 0 psi and 70 psi, the two extreme pressure cases. However, for the cases in between (30 and $50 \mathrm{psi}$ ), there are no peaks, which shows that these were better cured than the rest of the samples, or that the rate of heating did not affect the curing under these pressures.

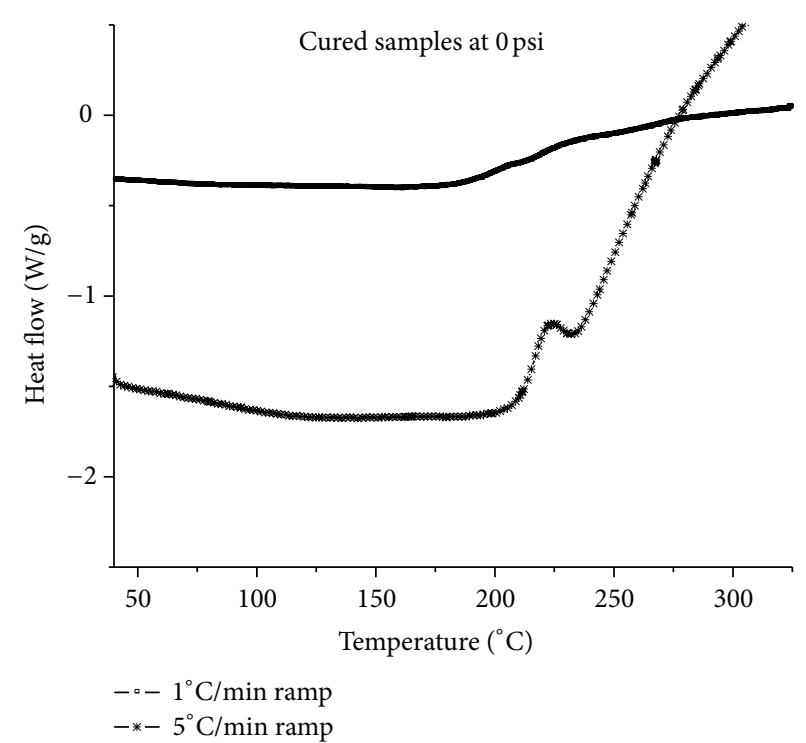

(a)

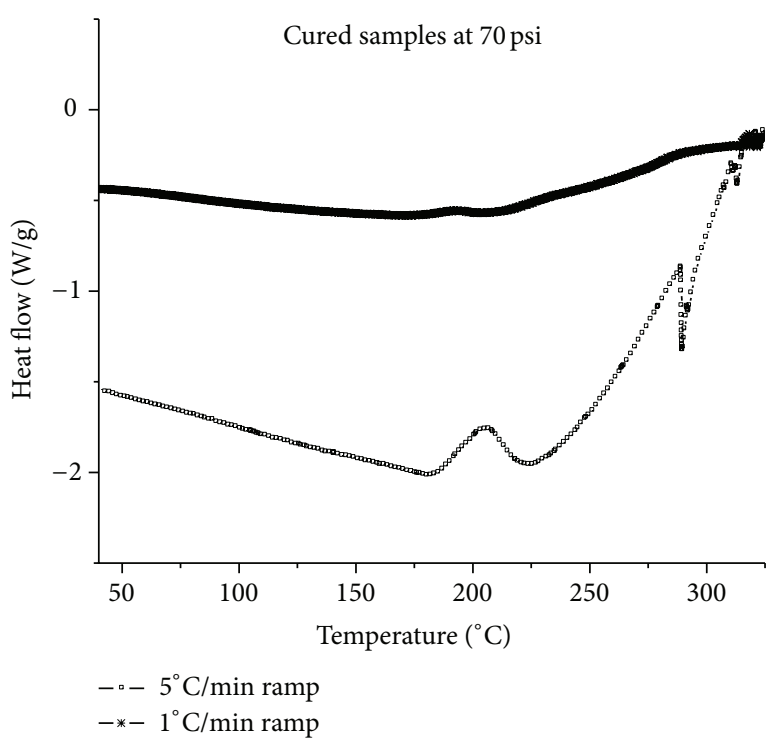

(b)

FIgURE 5: DSC scans at 1 and $5^{\circ} \mathrm{C} / \mathrm{min}$ for different pressure cases ((a) 0 psi; (b) 70 psi).

Again though, these indications are very random, and there is no conclusion that can be derived for the curing pressure and curing percentage relation. This observation can partly verify the conclusion that was made earlier regarding the pressure nonmonotonic effect on the curing percentage. Furthermore, it has also to be mentioned that the correlation of the DSC experiments of cured samples with the uncured ones gave a percentage of curing between 93\% and 99\%, not consistently distributed from 0 to $70 \mathrm{psi}$, which can also be concluded from the DSC graphs and can demonstrate the curing percentage independence from the curing pressure. 


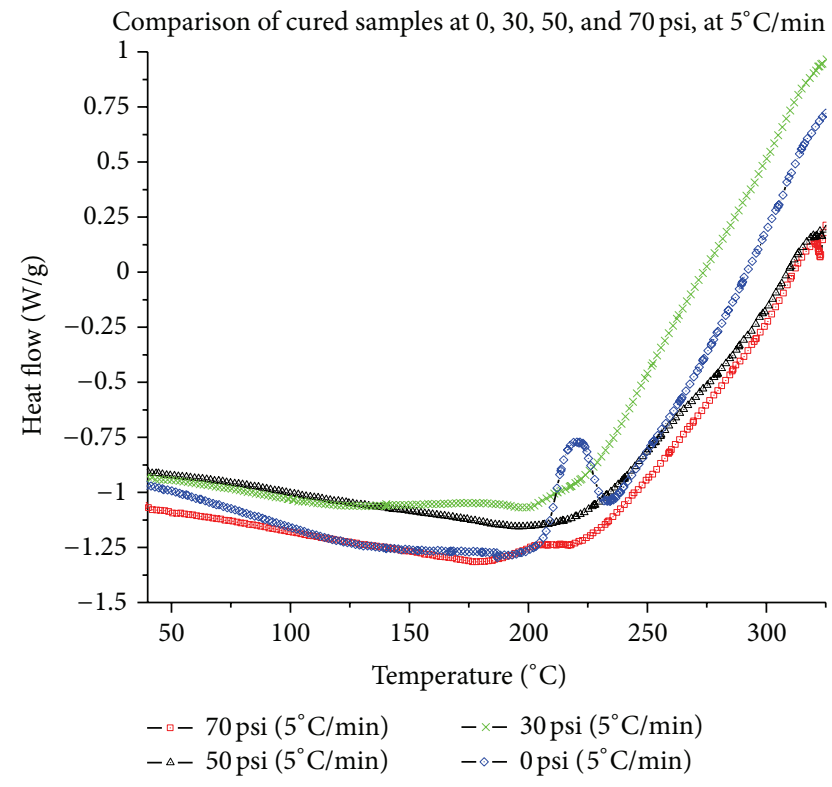

FIGURE 6: Eight plies samples comparison for the rate $5^{\circ} \mathrm{C} / \mathrm{min}$ at 0 , 30,50 , and 70 psi.

5.2. Microstructure Characterization. Scanning electron microscopy (Figures 7, 8, 9, and 10) clearly present void formation reduction in number and size as the manufacturing pressure increases.

5.3. Dynamic Mechanical Analysis. Graphs are provided to present the storage modulus (Figure 11) as well as $\tan \delta$ (Figure 13) of the samples manufactured in $0,30,50$, and 70 psi in 1 and $5^{\circ} \mathrm{C} / \mathrm{min}$.

It can be seen that there is a slight increase of the modulus while the manufacturing pressure increases, which is expected, as the higher the pressure, the less void formation within the composite. There are other factors such as density change, degree of curing, or glass transition temperature change, which one could think that may be responsible for this modulus increase; nevertheless, the first argument regarding the fewer voids with higher pressure is the most prevailing one as first, the density does not significantly vary with the pressure variation according to thermogravimetric analysis that has been performed [14] for the same specimens, second, the degree of curing is not affected by pressure as it has been seen through the DSC analysis, and finally, the glass transition temperature change is explained in Figure 12.

It is observed that the glass transition temperature decreases while the pressure increases. The glass transition reduction at $1^{\circ} \mathrm{C} / \mathrm{min}$ heating rate is in the order of around $30^{\circ} \mathrm{C}\left(T_{g}=206^{\circ} \mathrm{C}\right.$ at $70 \mathrm{psi}$ and $T_{g}=228^{\circ} \mathrm{C}$ at $\left.0 \mathrm{psi}\right)$. This difference expands when the heating rate increases to $5^{\circ} \mathrm{C} / \mathrm{min}$ in the order of around $50^{\circ} \mathrm{C}\left(T_{g}=180^{\circ} \mathrm{C}\right.$ at $70 \mathrm{psi}$ and $T_{g}=225^{\circ} \mathrm{C}$ at $0 \mathrm{psi}$ ).

This can be explained due to internal stresses [27] that the higher pressure imparts into the composite. Thus, the

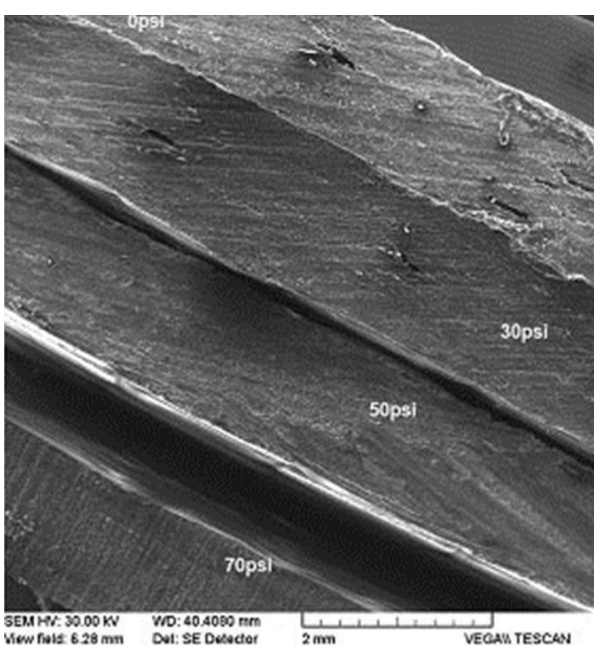

(a)

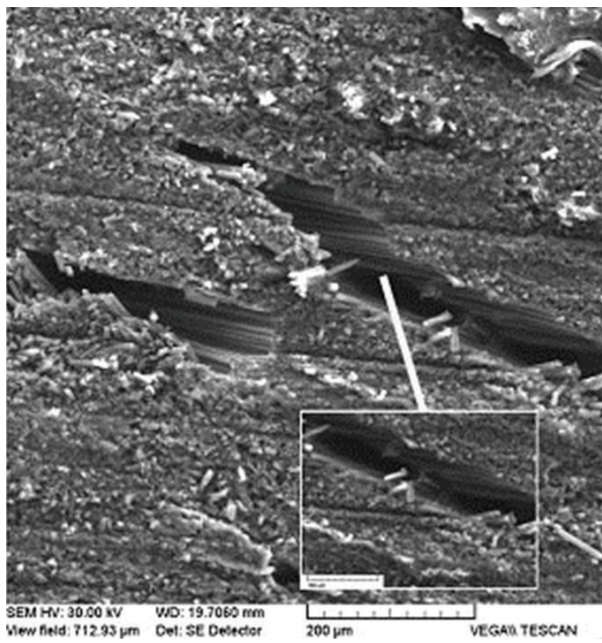

(b)

Figure 7: (a) All different samples manufactured in different pressures. (b) Samples manufactured at 0 psi, showing increased void formation.

temperature increase relieves the stresses and the material softens, leading to an apparent decrease of the glass transition temperature. This was verified by annealing the 70 psi manufactured samples at $220^{\circ} \mathrm{C}$ for an hour and then performing DMA at the $5^{\circ} \mathrm{C} / \mathrm{min}$ heating rate. The $T_{g}$ value was increased from $180^{\circ} \mathrm{C}$ to $214^{\circ} \mathrm{C}$, which is a value very close to the 0 psi manufactured sample (Figure 12).

Finally, the $\tan \delta$ of different manufacturing pressures at 1 and $5^{\circ} \mathrm{C} / \mathrm{min}$ heating rate is presented ( $\delta$ is the damping ratio, and $\tan \delta$ represents the loss over the storage modulus). The glass transition temperature presents similar behavior as in the storage modulus. Also, the damping from the 0 psi to 70 psi decreases for both heating rates, which correlates with the storage modulus slight increase while the manufacturing pressure increases.

The loss modulus (not shown here) influenced by the elastic energy that is lost to the environment basically decreases as the pressure increases presenting a proportional behavior 


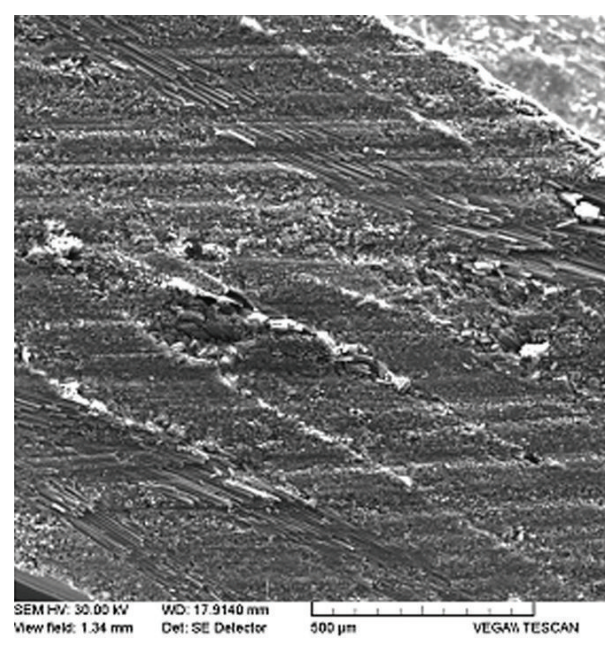

(a)

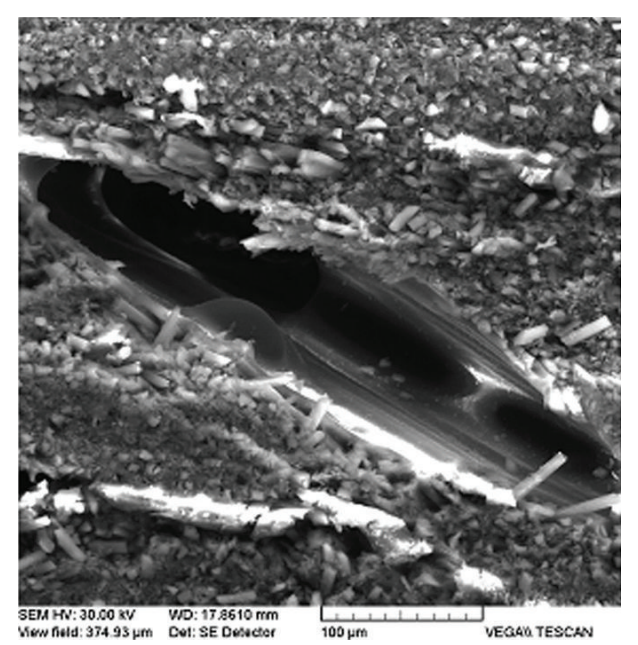

(b)

FIGURE 8: (a) The entire thickness cross-section of a sample manufactured at 30 psi. (b) Void also formed at 30 psi sample.

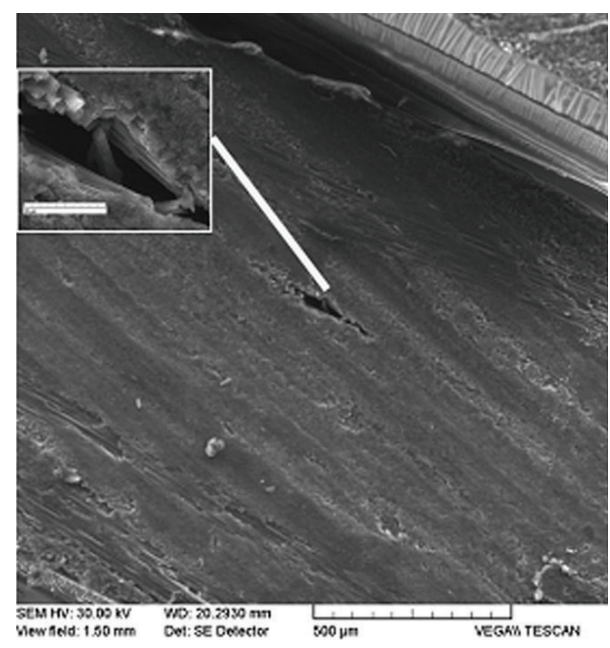

(a)

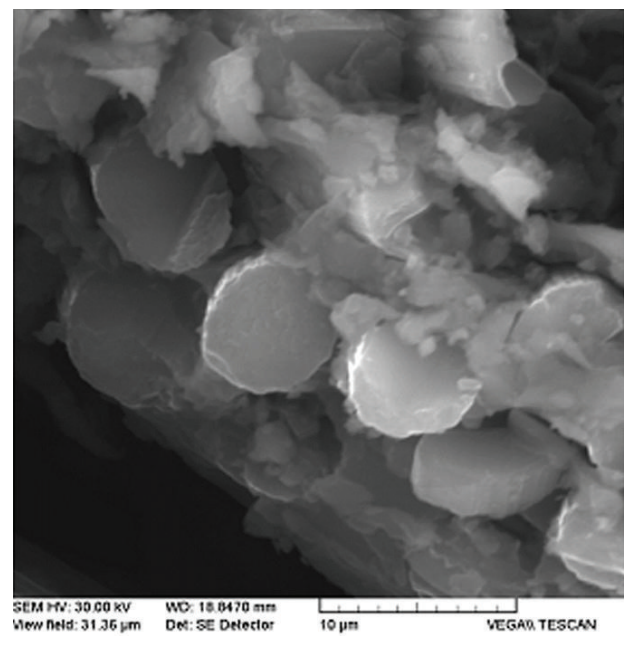

(b)

FIgURE 9: (a) The entire thickness cross-section of a sample manufactured at 50 psi. (b) Smaller voids also formed at 50 psi sample.

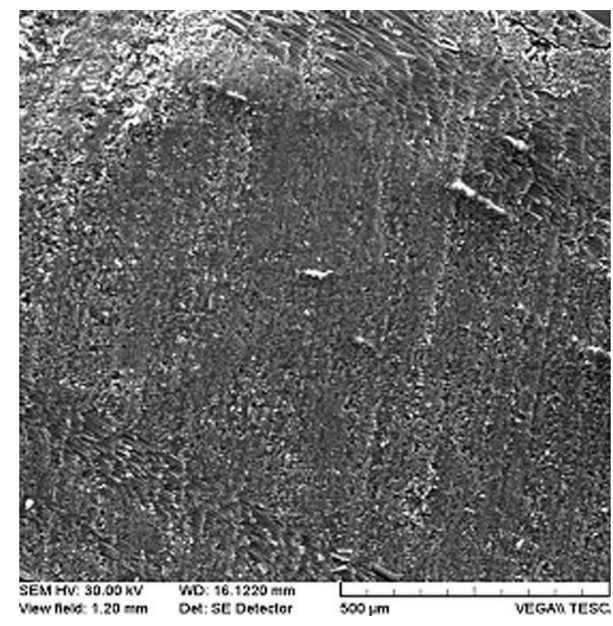

(a)

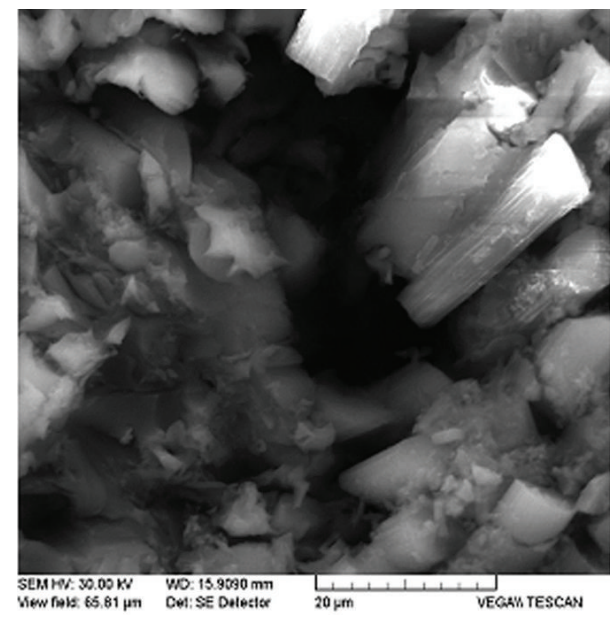

(b)

Figure 10: (a) The entire thickness cross-section of a sample manufactured at 70 psi. (b) Even smaller and less voids formed at 70 psi sample. 


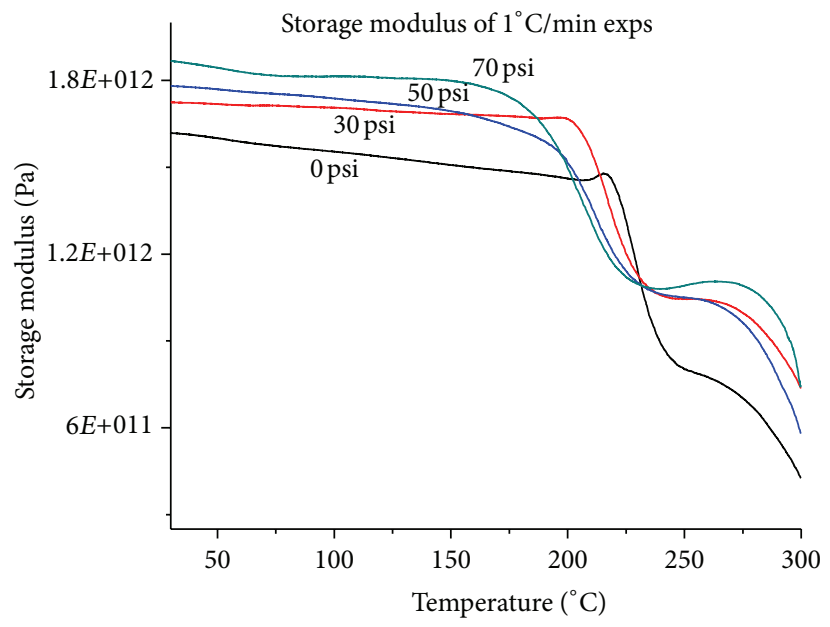

(a)

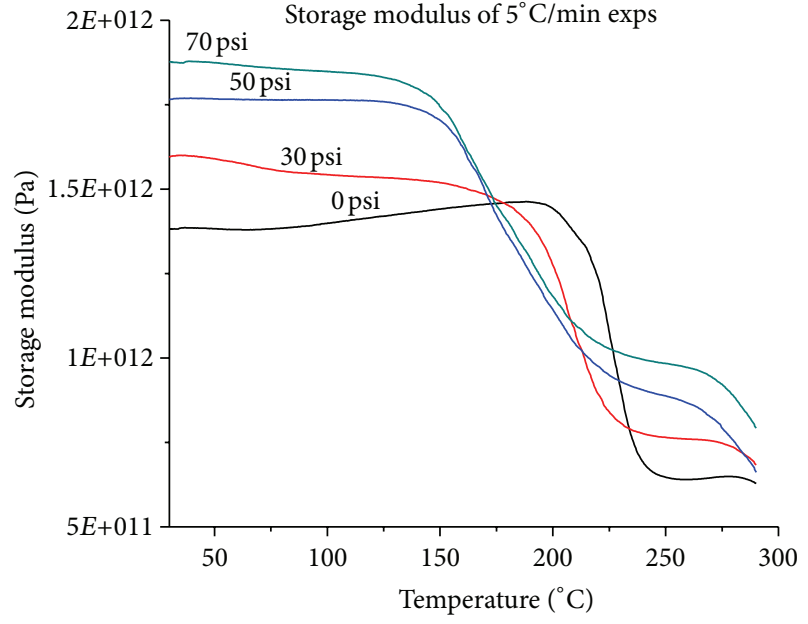

(b)

FIGURE 11: Storage modulus of carbon fiber prepregs -8 plies manufactured at $0,30,50$, and $70 \mathrm{psi}$ in 1 and $5^{\circ} \mathrm{C} / \mathrm{min}$.

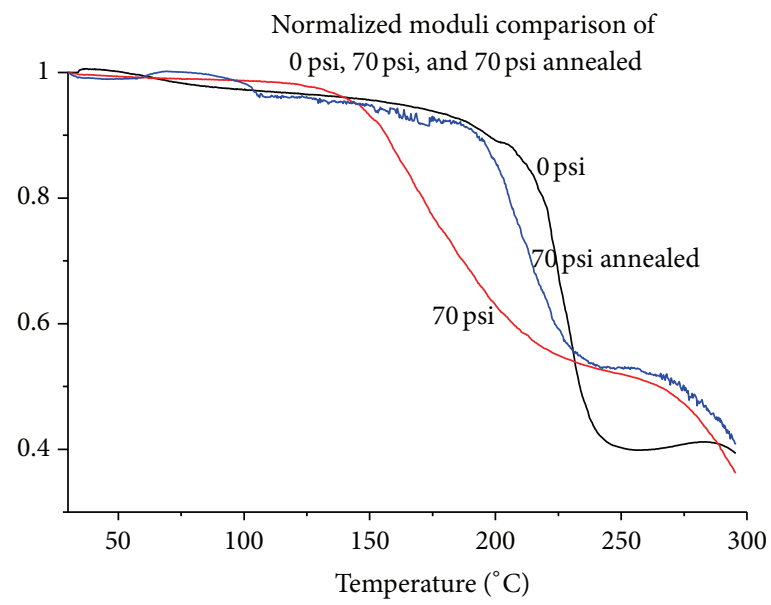

FIGURE 12: Normalized moduli comparison of $0 \mathrm{psi}, 70 \mathrm{psi}$, and $70 \mathrm{psi}$ annealed. $T_{g}$ of the annealed $70 \mathrm{psi}$ sample at $220^{\circ} \mathrm{C}$ is much closer to the 0 psi sample $T_{g}$.

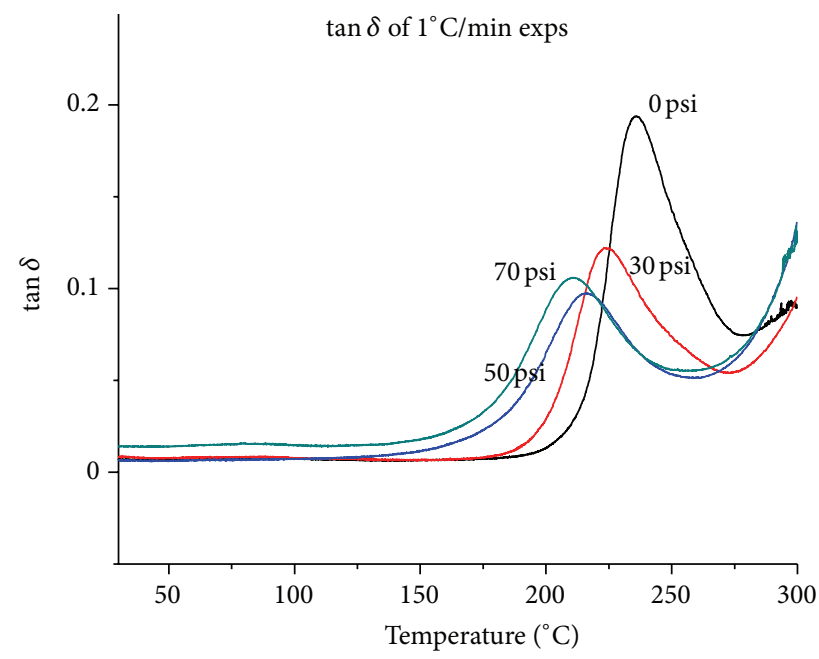

(a)

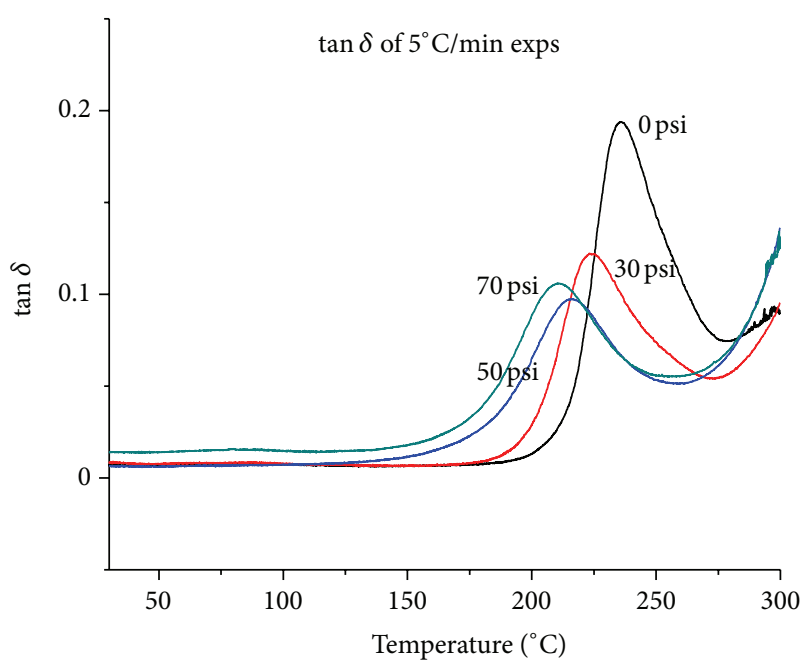

(b)

FIgURE 13: Storage modulus of carbon fiber prepregs -8 plies manufactured at $0,30,50$, and $70 \mathrm{psi}$ in 1 and $5^{\circ} \mathrm{C} / \mathrm{min}$. 


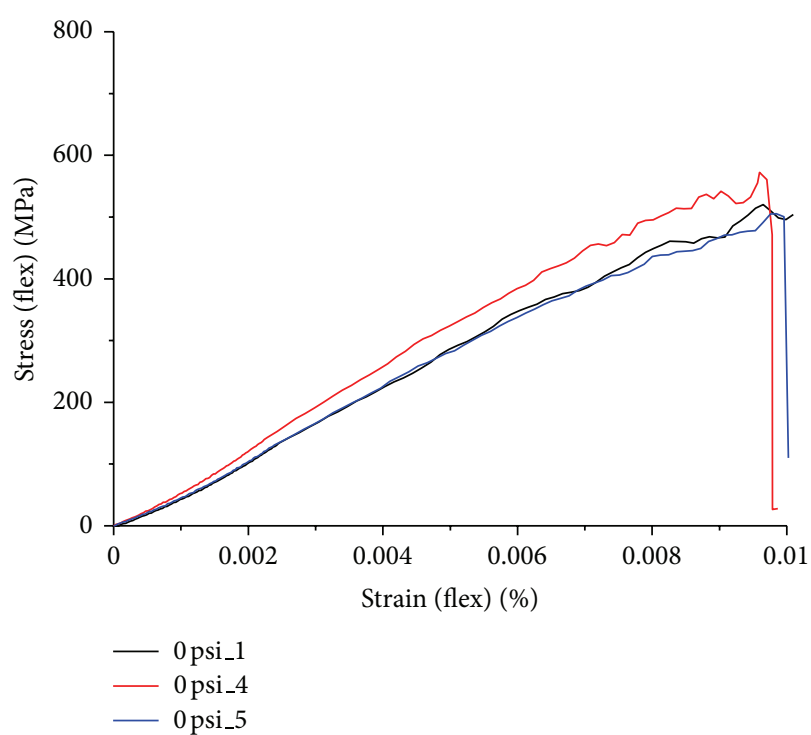

(a)

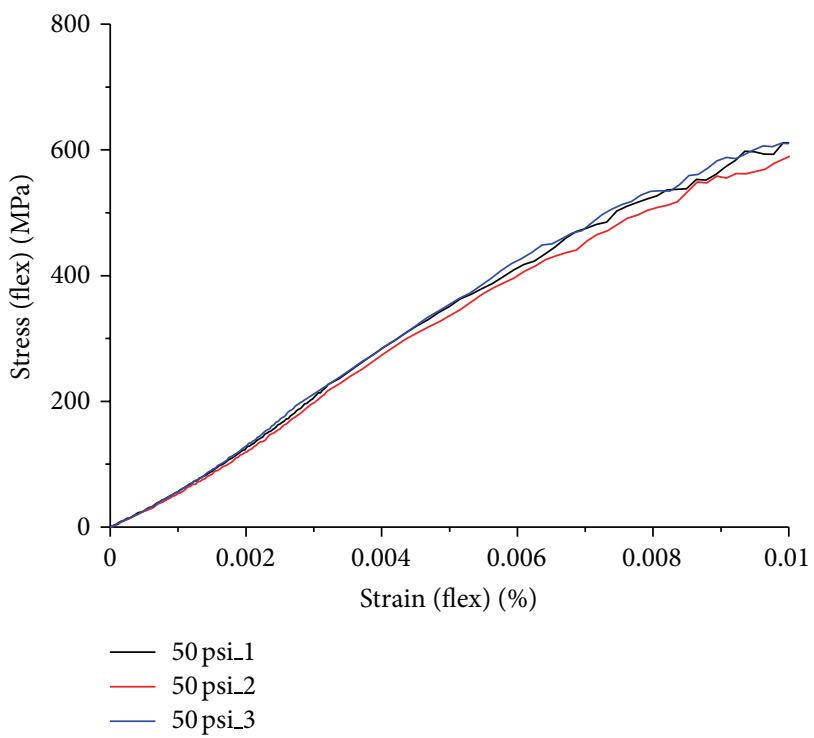

(c)

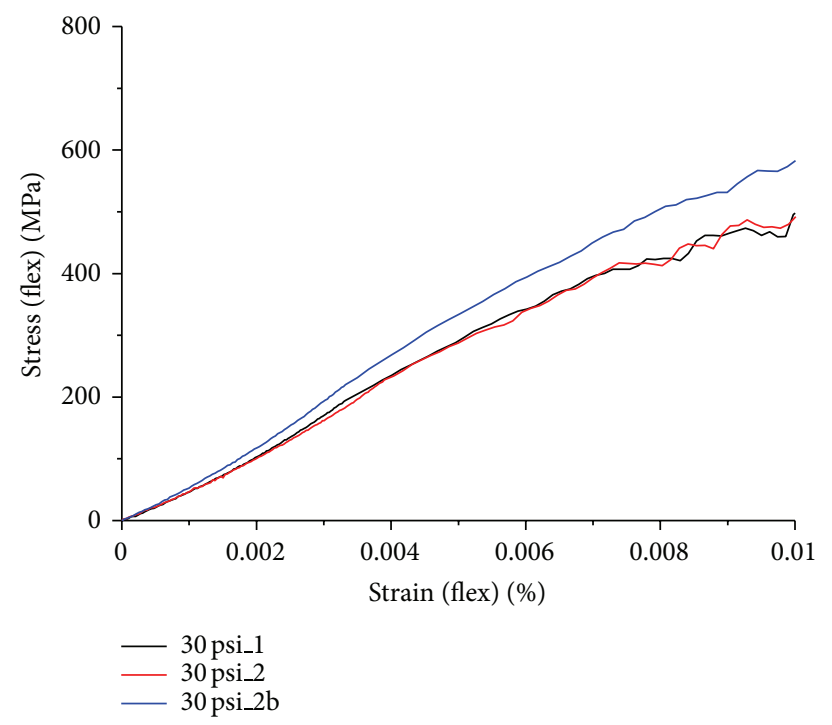

(b)

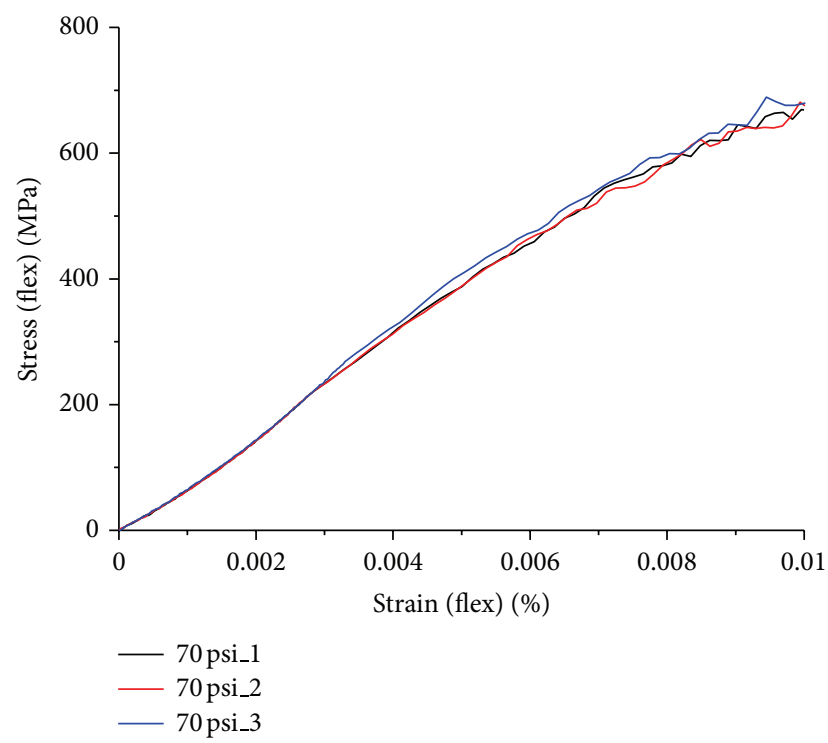

(d)

FIGURE 14: Flexural testing stress-strain curves for (a) 0 psi, (b) 30 psi, (c) 50 psi, and (d) 70 psi.

to $\tan \delta$. This is also expected as the higher the pressure while manufacturing, the higher alignment of the macromolecule chains within the composite, and as a result, the material softens in lower temperature presenting the loss modulus peak in a lower temperature [27].

5.4. Mechanical Testing. Two different tests were performed for the CFRP specimens manufactured under $0,30,50$, and $70 \mathrm{psi}$. As stated in the experimental description, the first testing was flexural mechanical testing (three-point bending). Figure 14 presents average specimens tested in each of the manufacturing pressures.

Following, in Figure 15, a comparison of the four different panels manufactured under $0,30,50$, and 70 psi in flexural mechanical testing is presented.
It can be seen that the specimens manufactured under 70 psi have a larger inclination than the specimens manufactured under 0 psi in relation to the strain axis, which is translated to a higher modulus.

The flexural modulus is calculated by (1):

$$
E_{f}=\frac{L^{\delta} \cdot F}{4 \cdot w \cdot h^{\delta} \cdot d}
$$

where $E_{f}$ is the flexural modulus $(\mathrm{MPa}), L$ is the gauge length $(\mathrm{mm}), w$ is the specimen cross-section width $(\mathrm{mm}), h$ is the specimen cross-section height $(\mathrm{mm}), F$ is the load $(\mathrm{N})$, and $\delta$ is the the deflection due to load $F(\mathrm{~mm})$.

By calculating the flexural modulus with type 2 applied for the elastic region of the stress-strain curve, the values of 
TABLE 3: Comparison of specimens manufactured in press-clave and autoclave.

\begin{tabular}{|c|c|c|c|c|c|}
\hline & $0 \mathrm{psi}$ & 30 psi & 50 psi & 70 psi & 85 psi autoclave processing \\
\hline Flexural modulus (GPa) & $41.8 \pm 6.08$ & $47 \pm 4.7$ & $51.67 \pm 1.53$ & $58.67 \pm 1.16$ & $60 \pm 2.3$ \\
\hline Flexural strength $(\mathrm{MPa})$ & $448.8 \pm 40.4$ & $522.46 \pm 42.35$ & $547.9 \pm 6.35$ & $613.4 \pm 21.8$ & $618 \pm 15.4$ \\
\hline Compression modulus (GPa) & $8.88 \pm 0.311$ & $9.96 \pm 0.38$ & $9.29 \pm 1.1$ & $9.02 \pm 2.22$ & $10.4 \pm 1.2$ \\
\hline Compression strength (MPa) & $42.1 \pm 2$ & $40.47 \pm 0.25$ & $39.97 \pm 1.07$ & $43.13 \pm 2.17$ & $44.5 \pm 1.05$ \\
\hline
\end{tabular}

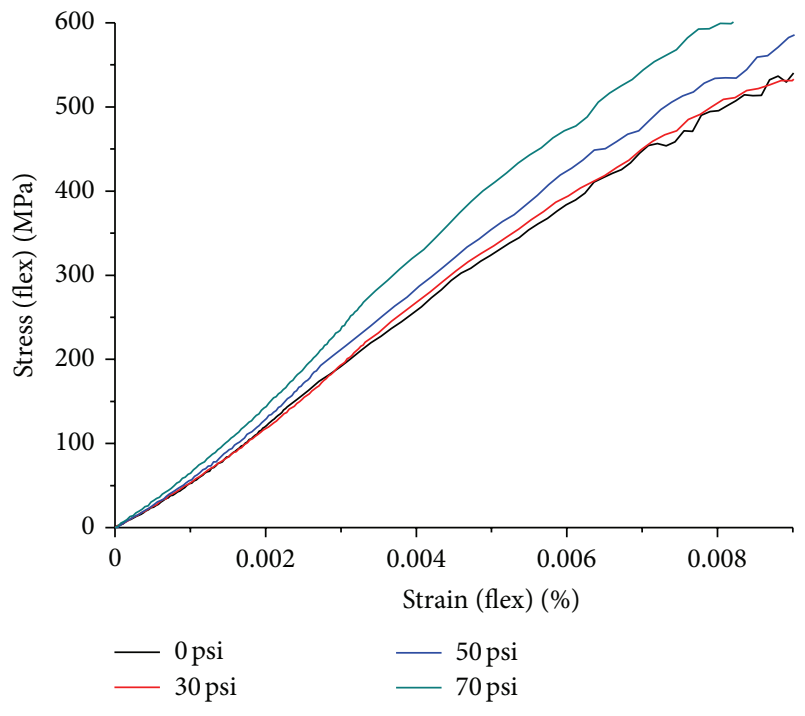

FIGURE 15: Stress-strain comparison of CFRP specimens manufactured under $0,30,50$, and 70 psi derived from flexural testing.

the flexural modulus are similar to the ones calculated by (1) as

$$
E_{f}=\frac{\sigma_{2}-\sigma_{1}}{\varepsilon_{2}-\varepsilon_{1}}
$$

where $\sigma_{1}$ and $\sigma_{2}$ are two random stress values on the stressstrain elastic region $\left(\sigma_{2}>\sigma_{1}\right)$, and $\varepsilon_{1}$ and $\varepsilon_{2}$ are two random strain values on the stress-strain elastic region $\left(\varepsilon_{2}>\varepsilon_{1}\right)$.

Equation (2) actually gives the direction coefficient of the stress-strain curve elastic region, which is the respective modulus.

Regarding the compression testing that was performed, Figure 16 presents the stress-strain curves of average specimens tested in each of the manufacturing pressures.

Following, in Figure 17, a comparison of the four different panels manufactured under $0,30,50$, and 70 psi in compression mechanical testing is presented.

It can be seen that there are no large differences in the inclination of the stress-strain curves at the elastic region. This means that the modulus of CFRPs manufactured under different pressures does not present significant changes in compression loads from low to higher pressures while manufacturing. The compression modulus is derived from (2), applied for the elastic region of the compression testing stressstrain curve.

The moduli and strength behaviour can also be seen in Table 3, where the average flexural and compression moduli and strengths for each of the CFRP panels are presented. Also, Table 3 illustrates mechanical testing results of specimens manufactured through conventional autoclave compared with those manufactured through the Press Clave. It can be seen that the high-pressure-70 psi-specimens present mechanical properties very similar to the autoclaved ones.

The results presented in Table 3 are statistically significant as well as the differences between the values of the specimens manufactured at $0,30,50$, and 70 psi. Linear regression analysis was performed for the experimental results. A level of significance at 0.15 was used to compare the results. It turned out that in all cases, the $P$ value of the regression analysis was below the 0.15 significance level, and as a result, the mechanical properties comparison shows statistically significant values and differences as a function of pressure. Taking the intervals of each group of experiments average through a double-sided $t$-test with a 0.15 level of significance, we are $85 \%$ confident that the values of the mechanical properties will lie within the range that is presented in Table 3 for each combination of property and pressure.

The analysis made throughout this section of innovative manufacturing with DSC, DMA, flexural and compression, and SEM characterizations gives the picture of the quality of composites manufactured through the press clave. DSC testing assures that composites are properly cured; DMA examines the viscoelastic behaviour of composites; flexural testing exhibits the stiffness improvement analogously with the higher manufacturing pressure; SEM gives information on the surface quality of the samples manufactured under different pressures. Furthermore, compression tests show that both modulus and strength under compression do not vary, and as a result, they are not affected by the different manufacturing pressure. Consequently, the well-cured specimens under the press-clave, the acceptable surface that they present in SEM characterization, and most importantly the slight differences in flexural strength and modulus under high-pressure manufacturing demonstrate that the press clave can be utilized as a decent alternative manufacturing process of the extremely expensive autoclave. Of course, this high-quality manufacturing through the press clave is achieved by the use of heat blankets, which are necessary for achieving the appropriate curing temperature profile while manufacturing and the thermal uniformity within the part while curing. The latter is very accurate in conventional autoclaves as it is very important for high-quality CFRP parts. Thus, the heat blanket is a mandatory tool in press clave manufacturing for accurate thermal uniformity within the part that is manufactured. Nevertheless, besides the obvious financial and other benefits from the utilization of heat blankets, their limitation compared to the heating system of an autoclave is the threedimensional and the complex geometry manufacturing of composite parts. 


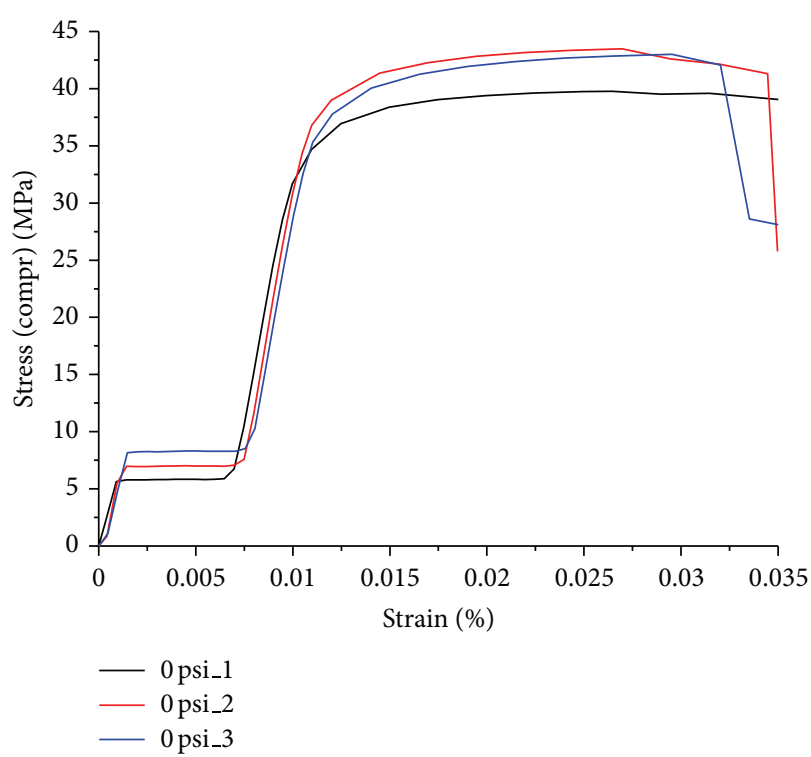

(a)

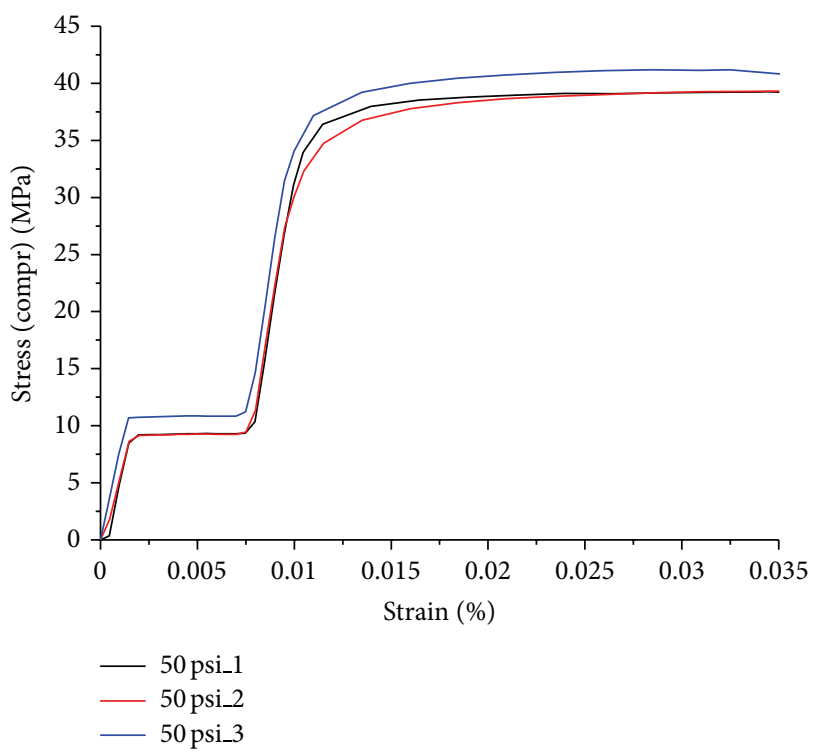

(c)

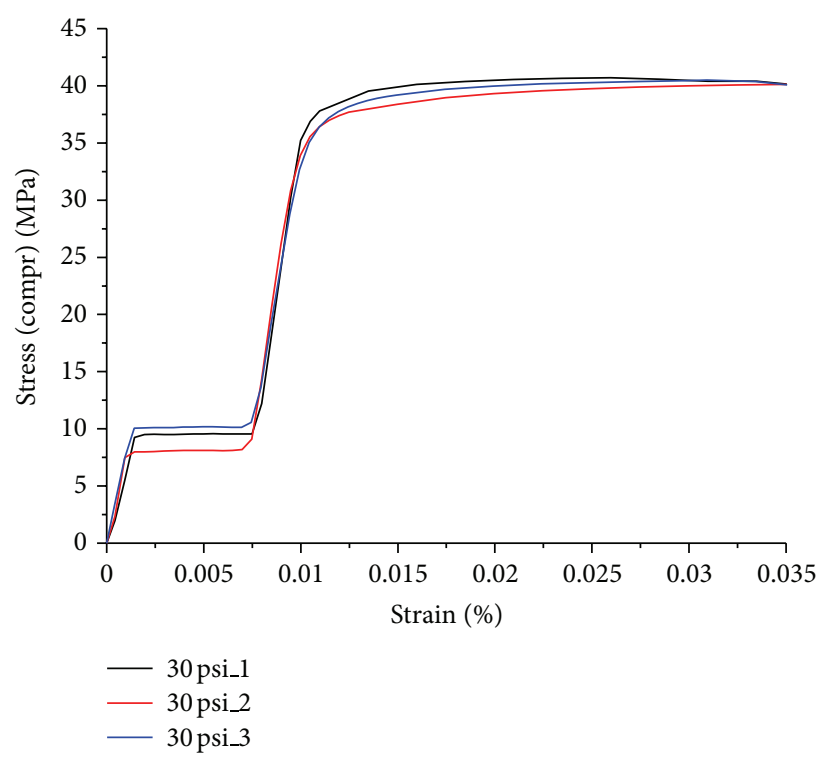

(b)

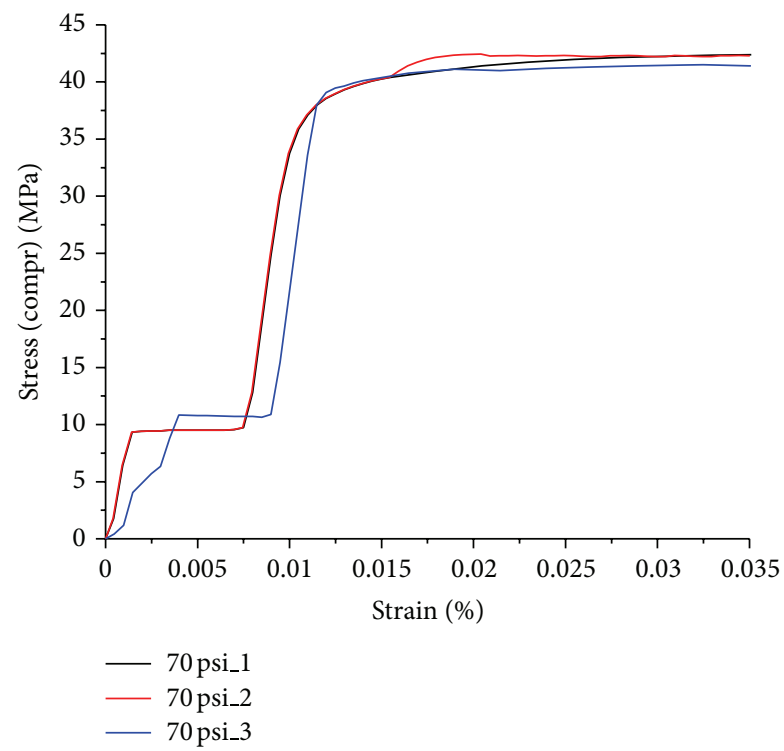

(d)

FIGURE 16: Compression testing stress-strain curves for (a) 0 psi, (b) 30 psi, (c) 50 psi, and (d) 70 psi.

\section{Conclusions}

The DSC results were not conclusive with respect to expected percentages of curing. It could not be concluded that the percentage of cure would be higher with a higher pressure, and also it was noticed that the differences from one pressure to another were quite small. These small differences could appear also because of the way the lay-up is done or the way the vacuum was maintained through the curing process. It is also possible that the differences are so small because of the small number of plies subjected to the experiments. An increased number of plies and an increased number of experiments could offer more definitive answers with respect to the influence of pressure on the manufacturing process of composite parts. In the future, it is planned to further investigate the press clave manufacturing technique and specifically test several specimens in DSC that have been manufactured with increased number of plies and more experiments to investigate the percentage of curing in several levels of the composite thickness, which will be demanded since the number of plies is increased.

Furthermore, the dynamic mechanical analysis DMA gives the expected results regarding the storage modulus reaction with the manufacturing pressure increase. The higher the manufacturing pressure the higher the modulus. However, there is a significant decrease in glass transition temperature as the manufacturing pressure, increases. This happens due to internal stresses formed in the materials when pressure 


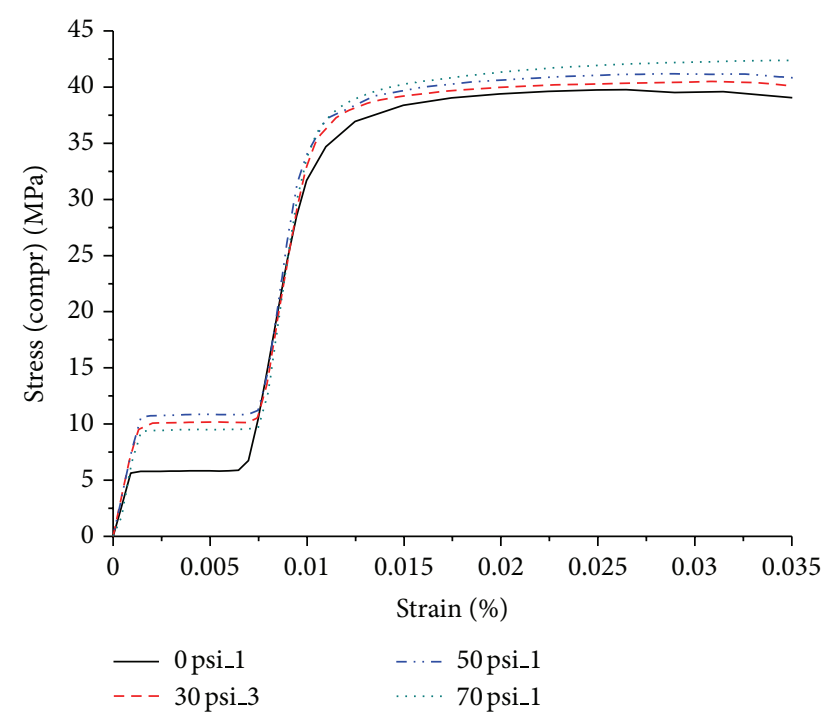

FIGURE 17: Stress-strain comparison of CFRP specimens manufactured under $0,30,50$, and 70 psi derived from compression testing.

is higher. Then, these internal stresses are relieved during heating and soften the material, resulting in a reduced $T_{g}$.

Additionally, scanning electron microscopy observation was performed for samples from all pressures. The results verified the storage modulus increase, as the higher the pressure, the less void formation. Finally, as far as the mechanical testing is concerned, the specimens under flexural testing exhibited a significant increase of both the flexural modulus and strength as the manufacturing pressure increases. On the other hand, the compression testing showed that the compression modulus is not dependent on the manufacturing pressure, and thus, besides a slight increase from 0 to 70 psi which is considered negligible, it presents relatively similar values for all the specimens. Similar behavior of manufacturing pressure independence is presented by the compression strength as well. The mechanical comparison with autoclaved samples exhibits the press clave potential as a curing alternative of the highly costly autoclave.

\section{References}

[1] E. J. García, A. J. Hart, B. L. Wardle, and A. H. Slocum, "Fabrication and nanocompression testing of aligned carbon-nanotube-polymer nanocomposites," Advanced Materials, vol. 19, no. 16, pp. 2151-2156, 2007.

[2] M. A. Tudela, P. A. Lagace, and B. L. Wardle, "Buckling response of transversely loaded composite shells, part 1: experiments," AIAA Journal, vol. 42, no. 7, pp. 1457-1464, 2004.

[3] J. C. Seferis, R. W. Hillermeier, and F. U. Buehler, Comprehensive Composite Materials, chapter 2.20, Elsevier, 2000.

[4] B. S. Hayes and J. C. Seferis, "Rubber toughening of epoxy-cyanate ester blends for VARTM applications," in Proceedings of the 59th SPE Annual Technical Conference and Exhibition, vol. 3, pp. 2940-2943, 2001.

[5] E. N. Gilbert, B.S. Hayes, and J.C. Seferis, "Characterization of VARTM resin candidates for commercial airplane applications," in Proceedings of the 33rd International SAMPE Technical Conference, pp. 1368-1378, 2001.

[6] E. P. M. Williams, B. S. Hayes, and J. C. Seferis, "VARTM processing of honeycomb sandwich composites: effect of SCRIM permeability," in Proceedings of the 33rd International SAMPE Technical Conference, pp. 1408-1414, 2001.

[7] R. Peila, S. S. Sangari, T. Karaki, J. C. Seferis, and G. Parker, "Rheological and morphological properties of VARTM (vacuum assisted resin transfer molding) epoxy resins/clay nanocomposites," in Proceedings of the Society of Plastics Engineers Annual Technical Conference (ANTEC '05), pp. 22-26, May 2005.

[8] K. J. Ahn, J. C. Seferis, and L. Letterman, "Autoclave resin infusion process. Analysis and prediction of resin content," SAMPE Quarterly, vol. 21, no. 2, pp. 3-10, 1990.

[9] K. Ishiguro, S. S. Sangari, and J. C. Seferis, "Microcrack initiation mechanism of CFRP under the thermal cycle," in Proceedings of the Creating New Opportunities for the World Economy (SAMPE '06), May 2006.

[10] K. Yoshioka, B. S. Hayes, and J. C. Seferis, "Fatigue damage in notched CFRP laminates processed by RTM," in Proceedings of the 33rd International SAMPE Technical Conference, pp. 601610, 2001.

[11] J.-A. E. Manson, T. L. Schneider, and J. C. Seferis, "Press-forming of continuous fiber-reinforced thermoplastic composites," Polymer Composites, vol. 11, no. 2, pp. 114-120, 1990.

[12] J. C. Seferis and K. Ahn, "Prepreg processing science and analysis," in Proceedings of the 34th International SAMPE Symposium, vol. 34, pp. 63-71, 1989.

[13] J. C. Seferis, C. N. Velisaris, and V. M. Drakonakis, "Prepreg manufacturing," in Wiley Encyclopedia of Composites, John Wiley \& Sons, 2011.

[14] V. M. Drakonakis, C. G. Ancuta, J. C. Seferis et al., in Proceedings of the International Conference on Structural Analysis of Advanced Materials (ICSAAM '09), Tarbes, France, September 2009.

[15] S.-B. Shim, K. J. Ahn, J. C. Seferis, A. J. Berg, and W. Hudson, "Flow and void characterization of stitched structural composites using Resin Film Infusion Process (RFIP)," Polymer Composites, vol. 15, pp. 453-463, 1994.

[16] M. G. Bader and J. R. Wood, "Void control for polymermatrix composites (1): theoretical and experimental methods for determining the growth and collapse of gas bubbles," Composites Manufacturing, vol. 5, pp. 139-147, 1994.

[17] F. Y. C. Boey and S. W. Lye, "Void reduction in autoclave processing of thermoset composites," Composites, vol. 23, pp. 261265, 1992.

[18] J. L. Kardos, M. P. Dudokovic, and R. Dave, Advances in Polymer Science, vol. 80, pp. 101-123, 1980.

[19] J. C. Halpin, J. L. Kardos, and M. P. Dudukovic, "Processing science: an approach for prepreg composite systems," in Proceedings of the IUPAC International Symposium on the Interrelations between Processing Structure and Properties of Polymeric Materials, J. C. Seferis and P. S. Theocaris, Eds., pp. 893-906, Athens, Greece, 1982.

[20] J. E. Shafizadeh, B. S. Hayes, J. C. Seferis, and M. Thompson, "Fundamentals of breather technology in prepreg consolidation," Journal of Advanced Materials, vol. 28, no. 3, pp. 42-49, 1997.

[21] B. S. Hayes and J. C. Seferis, "The effect of fabric tension and the number of impregnation rollers on woven fabric prepreg quality and cured laminates," Composites A, vol. 28, pp. 791-799, 1997. 
[22] A. B. Strong, Fundamentals of Composites Manufacturing, SME, Dearborn, Mich, USA, 1989.

[23] S.-B. Shim, J. C. Seferis, and W. Hudson, "Process induced void formation in a high performance structural composite system manufactured by autoclave lay-up processing," Journal of Advanced Materials, vol. 28, no. 4, pp. 26-36, 1997.

[24] S. Tzavalas, D. E. Mouzakis, V. Drakonakis, and V. G. Gregoriou, "Polyethylene terephthalate-multiwall nanotubes nanocomposites: effect of nanotubes on the conformations, crystallinity and crystallization behavior of PET," Journal of Polymer Science B, vol. 46, no. 7, pp. 668-676, 2008.

[25] F. U. Buehler and J. C. Seferis, "Heat diffusion analysis of the temperature distribution and phase lag build-up in TMDSC specimens," Thermochimica Acta, vol. 334, no. 1-2, pp. 49-55, 1999.

[26] F. U. Buehler and J. C. Seferis, "Thermal gradients in TMDSC samples a comparison of theory and experimental data," Journal of Thermal Analysis and Calorimetry, vol. 63, no. 1, pp. 21-30, 2001.

[27] J.-A. Manson and J. C. Seferis, "Internal stress determination by process simulated laminates," in Proceedings of the SPE (ANTEC '87), p. 1446, 1987.

[28] http://hcs.heatcon.com/proddetail.php?prod=HCS3100.

[29] http://www.thermalequipment.com/. 

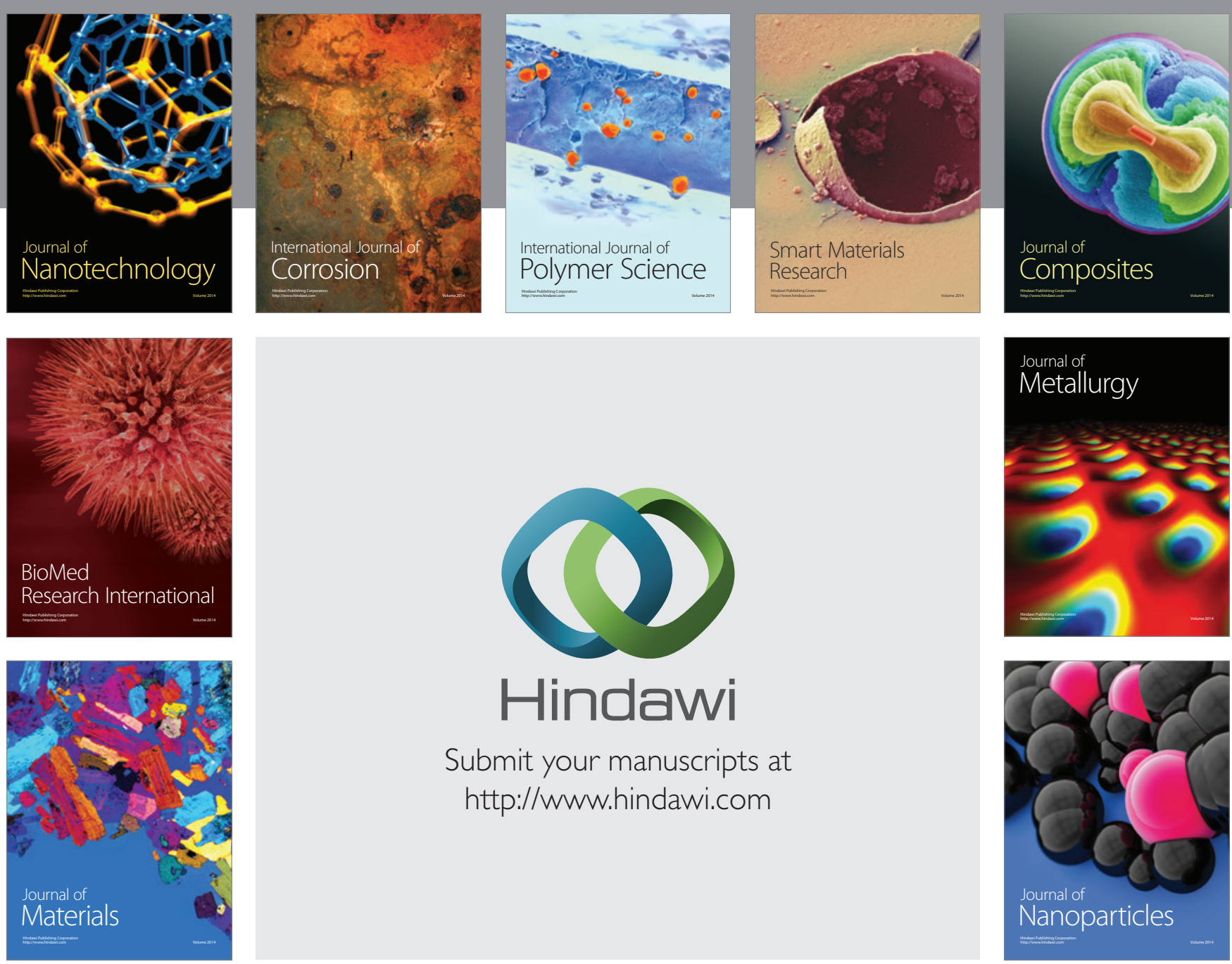

Submit your manuscripts at http://www.hindawi.com
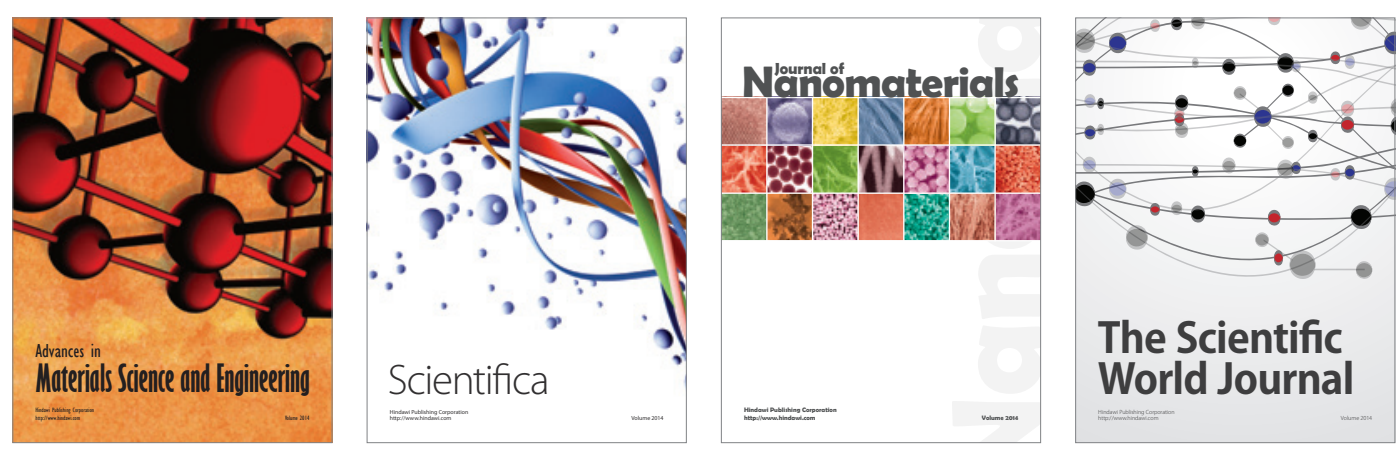

\section{The Scientific World Journal}
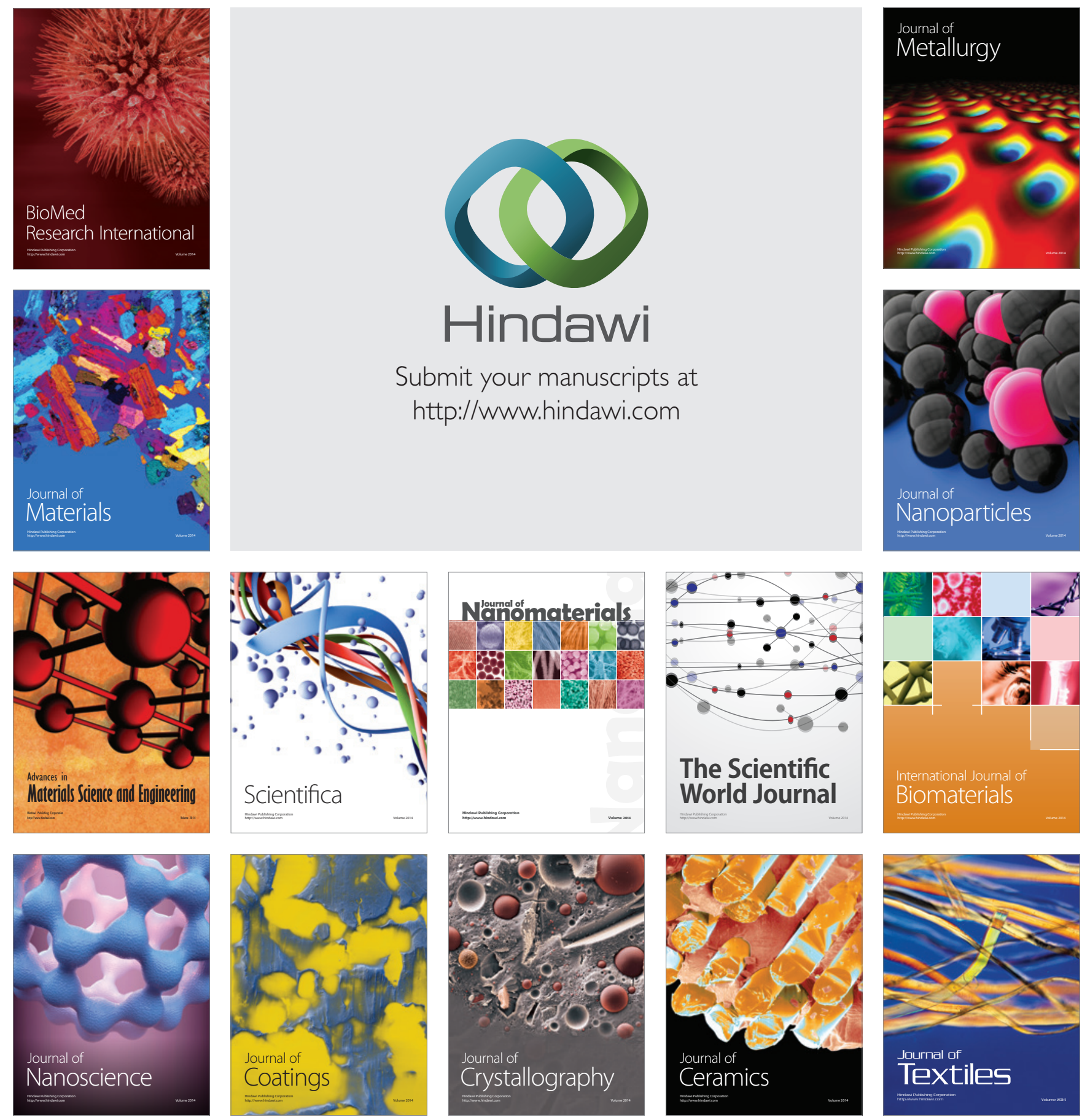